\title{
Early and Delayed Effect of Functional Endoscopic Sinus Surgery on Intraocular Pressure
}

\author{
Mohammad Waheed El-Anwar ${ }^{1}$ Mohammad Abdelhady ${ }^{1}$ Hazem Saeed Amer ${ }^{1}$ Manar A. Ghali ${ }^{2}$ \\ ${ }^{1}$ Department of Otorhinolaryngology - Head and Neck Surgery, \\ Faculty of Medicine, Zagazig University, Zagazig, Egypt \\ 2 Department of Ophthalmology, School of Medicine, Zagazig \\ University, Zagazig, Egypt \\ Address for correspondence Hazem Saeed Amer, MD, Department of \\ Otorhinolaryngology, Head and Neck Surgery, School of Medicine, \\ Zagazig University, Zagazig 0020552322665, Egypt \\ (e-mail: hazemamerent@yahoo.com).
}

Int Arch Otorhinolaryngol 2016;20:359-363.

\begin{abstract}
Introduction Due to the close anatomical relationship between the paranasal sinuses and the orbit, involvement or injury of the orbit from paranasal sinuses procedures may occur.

Objectives We aimed to study the early and delayed effect of endoscopic sinus surgery on intraocular pressure (IOP).

Methods We included in the study 38 patients with chronic rhinosinusitis (CRS), undergoing FESS. We performed FESS with the standard anterior to posterior approach. We measured IOP at the same time one day before surgery as well as day 1 and 6 weeks after surgery.

Results One day after surgery, mean IOP in the right eye was $14.176 \pm 1.91 \mathrm{~mm} \mathrm{Hg}$ and in the left eye was $13.79 \pm 2.42 \mathrm{~mm} \mathrm{Hg}$ with statistically non-significant difference from preoperative values. Six weeks postoperative, the mean IOP in the right eye was $15.14 \pm 2.28 \mathrm{~mm} \mathrm{Hg}$. The difference between the mean preoperative and postoperative IOP values was found to be statistically significant $(p=0.0012)$. While in the left eye, mean postoperative IOP was $15.14+2.23 \mathrm{~mm} \mathrm{Hg}$. The difference between the mean preoperative and postoperative IOP values was also found to be highly statistically

Keywords

- sinusitis

- nose

- endoscopy

significant $(p=0.0005)$.

Conclusion Delayed significant increase in IOP can occur after FESS, Thus, special measures must be taken to reduce IOP to protect the patients eye from the risk of increased IOP, especially in patients with glaucoma.
\end{abstract}

\section{Introduction}

Chronic rhinosinusitis (CRS) is one of the most common diseases in the otolaryngologic field. Functional endoscopic sinus surgery (FESS) represents the preferred surgical treatment for CRS. ${ }^{1}$

FESS was initially driven by Messerklinger's work in the late 1970 s. $^{2}$ It was then popularized and standardized in the beginning of the 1980s, particularly by Kennedy et $\mathrm{al}^{3}$ and
Stammberger ${ }^{4}$ with their studies regarding the philosophy of clearing the natural ostium of the diseased sinus.

Due to the close anatomical relationship between the paranasal sinuses and the orbit, involvement or injury of the orbit from procedures the paranasal sinuses may occur. ${ }^{5}$

The ocular complications after FESS include: nasolacrimal duct injury, extraocular muscle injury; periorbital, intraorbital, or retrobulbar hematoma; and even optic nerve injury. The risk of injury is correlated to the anatomical variations, the history of received

September 1, 2015

accepted

December 11, 2015

published online

February 26, 2016
DOI http://dx.doi.org/

10.1055/s-0036-1579663. ISSN 1809-9777.
Copyright (c) 2016 by Thieme Publicações License terms Ltda, Rio de Janeiro, Brazil 
previous surgery, the extent of the disease, and the skills of the surgeon. 6,7

Normal intraocular pressure (IOP) is essential for normal eye structure and function.

When the balance of aqueous formation and drainage is altered, IOP changes. The IOP elevation results in corneal edema, iris atrophy, cataract and optic nerve atrophy. The common symptoms of increased IOP are blurred vision, epiphora, headache, nausea, vomiting, or a sensation of pressure in the eyes. ${ }^{1}$

Some studies have described the relationships between conventional sinus surgery and IOP. ${ }^{8,9}$ A previous research ${ }^{1}$ described the early effect of FESS on IOP; however, in the current study, we aimed at detecting whether or not there is a delayed effect for this type of surgery on IOP.

\section{Patients and Methods}

Thirty-eight patients were included in this prospective study. All included patients were suffering from nasal polypi refractory to medical treatment (according to Lanza and Kennedy ${ }^{10}$ ) and had been scheduled for FESS. Exclusion criteria included patients that had diabetes mellitus, hypertension, glaucoma, ocular hypertension, previous ocular trauma, history of ocular surgery, defect in lamina paperatia, and patients within two days of using topical corticosteroid eye drops. Any systemic conditions, such as carotid-cavernous fistula and pulmonary hypertension, which may induce changes in episcleral venous pressure were also excluded because the fluctuation of episcleral venous pressure results in changes in IOP.

All patients included in this study signed an informed consent. All patients underwent medical history analysis, examination, diagnostic nasal endoscopy, and CT. We classified nasal polyps following the staging classification proposed by Johansson et $\mathrm{al}^{11}$; level 0 - absent, level I - polyp in the middle meatus, level II - polyp going through the middle turbinate with clear nasal floor, level III - polyp filling up the entire nasal cavity.

\section{Surgical Procedure}

Each nasal cavity was packed (in middle meatus) with a piece of gauze soaked with topical vasoconstrictor (with adrenaline dissolved in saline in a concentration of $1: 200,000$.) fifteen minutes before surgery, to be removed at the beginning of surgery.

We performed all surgeries under general anesthesia with oral endotracheal tube with the standard anterior to posterior approach for FESS (middle meatal antrostomy, anterior ethmoidectomy, posterior ethmoidectomy, sphenoidotomy, skull base clearance, and/or frontal sinus clearance). Used intranasal packing was removed on the first morning after surgery. We prescribed postoperative antibiotics and analgesics.

IOP was measured for both eyes in all patients using Goldmann applanation tonometry, and dilated funduscopy as baseline data one day before surgery. Then, we measured IOP on day 1 postoperatively and, lastly, at 6 weeks after surgery.

\section{Statistical Analysis}

We used the SPSS statistical software package (version 18.0; SPSS, Inc., Chicago, IL, USA) for statistical comparisons and descriptive statistics. A $p$ value $<0.05$ was considered statistically significant.

\section{Results}

This study included 38 patients: 22 males (57.9\%) males and 16 females (42.1\%). Their ages ranged from 16 to 56 years with a mean of 35.3 years.

All patients underwent preoperative endoscopic nasal examination (76 nasal sides) and various grades of nasal polyposis were detected. Grade 0 was detected in 12 nasal sides (15.8\%), grade 1 in 18 sides (23.7\%), grade 2 in 28 sides (36.8\%), and grade 3 in 18 sides (23.7\%) (- Table $\mathbf{1}$ ).

No major complications were observed in this study; only minor complications in the form of nasal adhesions between the inferior turbinate and septum (in two cases).

Moreover, we found no significant correlation between the postoperative changes in IOP values and the grades of nasal polyposis $\left(R\right.$ value $=0.3521 ; R^{2}$, the coefficient of determination, was 0.124$)$.

We found that the mean preoperative pressure was $13.1 \pm 2.5 \mathrm{~mm} \mathrm{Hg}$ (range, $10-18 \mathrm{~mm} \mathrm{Hg}$ ) in the right eye and $12.89 \pm 2.23 \mathrm{~mm} \mathrm{Hg}$ (range, $10-17 \mathrm{~mm} \mathrm{Hg}$ ) in the left eye, and the difference between the mean IOP values between the two sides was found to be statistically non-significant $(p=0.7862, t=0.2732)$ ( - Tables 2 and $\mathbf{3})$.

One day after surgery, the mean postoperative IOP in the RT eye was $14.176 \pm 1.91 \mathrm{~mm} \mathrm{Hg}$ (range $10-17 \mathrm{~mm} \mathrm{Hg}$ ) and the difference between the mean preoperative and postoperative IOP values was statistically non-significant $(p=0.1589$, $\mathrm{t}=1.4403$ ), whereas in the left eye mean postoperative IOP was $13.79 \pm 2.42 \mathrm{~mm} \mathrm{Hg}$ (range $10-19 \mathrm{~mm} \mathrm{Hg}$ ). The difference between the mean preoperative and postoperative IOP values was also statistically non-significant $(p=0.0961$, $t=1.6859$ ). Also, we observed that the difference in the postoperative IOP values between both eyes one day after surgery was statistically non-significant $(p=0.4428$, $\mathrm{t}=0.7718$ ) (-Table 2).

Six weeks after surgery, the mean postoperative IOP in the right eye was $15.14 \pm 2.28 \mathrm{~mm} \mathrm{Hg}$ (range $10-18 \mathrm{~mm} \mathrm{Hg}$ ) and the difference between the mean preoperative and postoperative IOP values was found to be statistically significant $(p=0.0012, t=3.4027)$, whereas in the left eye the mean postoperative IOP was $15.14286 \pm 2.23 \mathrm{~mm} \mathrm{Hg}$ (range 11 - $18 \mathrm{~mm} \mathrm{Hg}$ ). The difference between the mean

Table 1 Results of endoscopic nasal examination

\begin{tabular}{|l|l|l|}
\hline Grade of nasal polyp & Number of nasal sides & $\%$ \\
\hline 0 & 12 & 15.8 \\
\hline 1 & 18 & 23.7 \\
\hline 2 & 28 & 36.8 \\
\hline 3 & 18 & 23.7 \\
\hline
\end{tabular}


Table 2 Difference in IOP between preoperative and 1 day postoperative

\begin{tabular}{|l|l|l|l|l|l|l|l|}
\hline & \multicolumn{2}{l|l}{$\begin{array}{l}\text { Pre-operative IOP } \\
\text { (38 patients) }\end{array}$} & \multicolumn{2}{l|}{$\begin{array}{l}\text { 1 day post-operative } \\
\text { IOP (38 patients) }\end{array}$} & t test & value & Significance \\
\hline & Mean & SD & Mean & SD & & & \\
\hline Right & 13.1 & 2.5 & 14.176 & 1.91 & 1.4403 & 0.1589 & Non-Significant \\
\hline Left & 12.89 & 2.23 & 13.79 & 2.42 & 1.6859 & 0.0961 & Non-Significant \\
\hline
\end{tabular}

Abbreviations: IOP, intraocular pressure; SD, standard deviation.

Table 3 Difference in IOP between preoperative and 6 weeks postoperative

\begin{tabular}{|l|l|l|l|l|l|l|l|}
\hline & \multicolumn{2}{|l|}{$\begin{array}{l}\text { Pre-operative } \\
\text { IOP } \\
\text { (38 patients) }\end{array}$} & \multicolumn{2}{l|}{$\begin{array}{l}\text { 6 w post-operative } \\
\text { IOP } \\
\text { (28 patients) }\end{array}$} & t test & $p$ value & Significance \\
\hline & Mean & SD & Mean & SD & & & \\
\hline Right & 13.1 & 2.5 & 15.14 & 2.28 & 3.4027 & 0.0012 & Significant \\
\hline Left & 12.89 & 2.23 & 15.14 & 2.34872 & 3.6808 & 0.0005 & Extremely statistically significant \\
\hline
\end{tabular}

Abbreviations: IOP, intraocular pressure; SD, standard deviation; w, week.

preoperative and postoperative IOP values was also highly statistically significant ( $p$ value $=0.0005, \mathrm{t}=3.6808$ ). Moreover, the difference in the postoperative IOP values between right and left eyes 6 weeks after surgery was statistically non-significant.

We also performed endoscopic nasal examination during follow-up until 6 weeks after surgery for a second-look evaluation. The results presented no significant findings.

\section{Discussion}

Functional endoscopic sinus surgery (FESS) has gained popularity in the diagnosis and treatment of paranasal sinus diseases. ${ }^{12}$ However, orbital negative sequels may occur due to its close anatomical relation with the paranasal sinuses. ${ }^{5}$

The incidence of serious complications of endoscopic sinus surgery reportedly reaches $0.5 \%$. Orbital injuries can range from eye pressure, pain, retrobulbar hemorrhage, and compromised extraocular muscle movement with sequential binocular diplopia to blindness. ${ }^{13-16}$

Intraocular pressure (IOP) may be defined as the resulting balance between aqueous humor production and removal. Its increase is considered to be one of the main risk factors leading to the development of glaucoma. IOP is a variable value affected by multiple factors: age, gender, race, tobacco consumption, local ocular problems, obesity, hormonal changes, and physical exercise, among others. ${ }^{17-19}$

No clear line exists between safe and unsafe IOPs. In general, in cases in which the IOP is less than $30 \mathrm{~mm} \mathrm{Hg}$, the eye can be observed, and in cases in which the IOP is more than $40 \mathrm{~mm} \mathrm{Hg}$, a poor vision result may ensue.

The IOP can be measured clinically by various types of tonometers, including the Goldmann applanation tonometer, noncontact tonometer, and Tonopen. The Goldmann applanation tonometer is the most valid and reliable. ${ }^{20}$ That is why we used it in current study.
In the current study, the mean preoperative IOP rose 1 day postoperatively, but this increase was found to be statistically non-significant. In contrast, six weeks after surgery, we had noticed that the mean IOP increased in both eyes and this increase, surprisingly, was statistically significant in both eyes.

The postoperative results one day after surgery of this study agree with the results of Lin et al, ${ }^{1}$ who found also that the postoperative increase in the average IOP values is statistically non-significant, taking into consideration that Lin et $\mathrm{al}^{1}$ studied the early effect of FESS on IOP as they measured IOP in three consecutive days after surgery.

The mechanism by which IOP is raised post-FESS whether in the early or late postoperative period is not clearly understood. Vascular mechanism is one of the proposed mechanisms for increased IOP post FESS. The eyes and paranasal sinuses are anatomically, neighboring structures. The eyeball, orbit, and parts of the sinonasal areas share the same vascular supply from the ophthalmic artery.

The venous drainage of the orbit and ocular structures is via the central retinal vein (drains into the superior ophthalmic vein) and the vortex vein (drains into the inferior ophthalmic vein). The vascular supplies of the sinuses are partial from the anterior and posterior ethmoidal arteries those are also derived from the ophthalmic artery, and the anterior and posterior ethmoidal veins drain into the superior ophthalmic vein. ${ }^{21}$

Lin et $\mathrm{al}^{1}$ observed that the post-FESS symptoms of epiphora and eye pressure were similar to the symptoms of increased IOP. Given that the eyes and sinonasal region have the same origin of vascular supply, they decided to elucidate whether FESS would result in a significant change in the IOP before and after surgery. They detected increased IOP. In the early postoperative period, in agreement with the current study, these changes were statistically insignificant.

A possible cause of increased IOP postoperatively could be excessive gauze packing and overinflated antral balloons of the Foley type, after the Caldwell-Luc operation. This may induce 
hypertropia and compression of the central retinal artery. Gelman et $\mathrm{al}^{8}$ reported a case of acute ocular hypertension following the use of an antral balloon after repairing fractures on the floor of the orbit via a Caldwell-Luc antrostomy.

Another study was done by Papangelou and Christidis ${ }^{9}$ to investigate whether there would be any effects on the IOP in patients who underwent a Caldwell-Luc operation for chronic sinusitis or antral polyps. They found that some changes of IOP occurred whether or not the maxillary sinus walls were denuded of mucous membrane.

They performed endoscopic grading for nasal polyposis preoperatively and observed various grades; however, when correlating the postoperative changes in IOP values with the grades of nasal polyposis, they found no correlation.

Many researchers studied the effect of endotracheal intubation on IOP and found a transient increase in the IOP intraoperatively and in the early postoperative period. Malti and Geeta $^{22}$ reported that endotracheal intubation is associated with tachycardia, hypertension, and increase in intraocular pressure and that the latter may not have any adverse effect in patients with healthy eyes but has deleterious effects on a diseased or an injured eye. They also concluded in their study that laryngeal mask airway insertion is a suitable alternative to endotracheal intubation in patients having penetrating eye injuries, glaucoma, and strabismus in whom elevation of intraocular pressure is likely to be detrimental.

Langham et $\mathrm{al}^{23}$ and Murphy ${ }^{24}$ stated that endotracheal intubation can lead to adrenergic stimulation may cause vasoconstriction and an increase in central venous pressure which has a closer relationship to intraocular pressure than systemic pressure. It can produce an acute increase in intraocular pressure by increasing the resistance to the outflow of aqueous humor in the trabecular meshwork between the anterior chamber and the Schlemm's canal.

In fact, these mechanisms would explain the early increase in IOP. Nonetheless, the cause of delayed increase in IOP remains unclear, so further studies are needed to explain the effect in IOP post-FESS.

To the best of our knowledge, this the first study to deal with the delayed effect of FEES on IOP. However, further studies are still needed to study the delayed effect of FESS on IOP in unilateral cases, as our study only included cases with bilateral sinonasal pathology.

It is important to note the risk of potential rise of IOP after surgery in patients scheduled for FESS and that had preoperative increase IOP, such as patients of glaucoma. Thus, preoperative ophthalmological consultation is important to protect the patient from the hazard of possible increased IOP.

\section{Conclusion}

Delayed significant increase in IOP can occur after FESS. Therefore, special measures are necessary preoperatively to reduce IOP and protect the patient's eye from the hazard of increased IOP, especially in patients with glaucoma. Further studies are still needed to explain the cause of this delayed significant rise in IOP post-FESS.

\section{Conflict of Interest}

The authors declare no conflict of interest.

Financial Support

The authors declare no financial support or interest to this study.

\section{References}

1 Lin PW, Lin HC, Chang HW, Su CY. Effects of functional endoscopic sinus surgery on intraocular pressure. Arch Otolaryngol Head Neck Surg 2007;133(9):865-869

2 Messerklinger W. [Endoscopy of the nose]. Monatsschr Ohrenheilkd Laryngorhinol 1970;104(10):451-456

3 Kennedy DW, Zinreich SJ, Rosenbaum AE, Johns ME. Functional endoscopic sinus surgery. Theory and diagnostic evaluation. Arch Otolaryngol 1985;111(9):576-582

4 Stammberger H. Endoscopic endonasal surgery-concepts in treatment of recurring rhinosinusitis. Part I. Anatomic and pathophysiologic considerations. Otolaryngol Head Neck Surg 1986; 94(2):143-147

5 Colclasure JC, Gross CW, Kountakis SE. Endoscopic sinus surgery in patients older than sixty. Otolaryngol Head Neck Surg 2004; 131(6):946-949

6 Bhatti MT, Giannoni CM, Raynor E, Monshizadeh R, Levine LM. Ocular motility complications after endoscopic sinus surgery with powered cutting instruments. Otolaryngol Head Neck Surg 2001; 125(5):501-509

7 Stankiewicz JA. Blindness and intranasal endoscopic ethmoidectomy: prevention and management. Otolaryngol Head Neck Surg 1989;101(3):320-329

8 Gelman HK, Janzen WR, Skolnik EM. Ocular hypertension following use of an antral balloon. Arch Otolaryngol 1974; 99(6):449-450

9 Papangelou L, Christidis M. Positive intramaxillary sinus pressure and intraocular pressure. J Laryngol Otol 1978; 92(12):1071-1074

10 Lanza DC, Kennedy DW. Adult rhinosinusitis defined. Otolaryngol Head Neck Surg 1997;117(3 Pt 2):S1-S7

11 Johansson L, Akerlund A, Holmberg K, Melén I, Stierna P, Bende M. Evaluation of methods for endoscopic staging of nasal polyposis. Acta Otolaryngol 2000;120(1):72-76

12 Weber R, Draf W, Keerl R, Schick B, Saha A. Endonasal microendoscopic pansinusoperation in chronic sinusitis. II. Results and complications. Am J Otolaryngol 1997;18(4):247-253

13 Cumberworth VL, Sudderick RM, Mackay IS. Major complications of functional endoscopic sinus surgery. Clin Otolaryngol Allied Sci 1994;19(3):248-253

14 Graham SM, Nerad JA. Orbital complications in endoscopic sinus surgery using powered instrumentation. Laryngoscope 2003; 113(5):874-878

15 Huang CM, Meyer DR, Patrinely JR, et al. Medial rectus muscle injuries associated with functional endoscopic sinus surgery: characterization and management. Ophthal Plast Reconstr Surg 2003;19(1):25-37

16 Stankiewicz JA. Complications in endoscopic intranasal ethmoidectomy: an update. Laryngoscope 1989;99(7 Pt 1):686-690

17 Fernández PC. Glaucoma. Medicine 1998;7:4770-4777.1987; 97: 1270-1273

18 Qureshi IA. Intraocular pressure: a comparative analysis in two sexes. Clin Physiol 1997;17(3):247-255

19 Passo MS, Goldberg L, Elliot DL, Van Buskirk EM. Exercise conditioning and intraocular pressure. Am J Ophthalmol 1987;103(6): 754-757 
20 Liesegang TJ, Skuta GL, Cantor LB. Basic and Clinical Science Course, Section 10 Glaucoma: Intraocular Pressure and Aqueous Humor Dynamics. San Francisco, CA: American Academy of Ophthalmology; 2003:14-24

21 Harris A, Jonescu-Cuypers CP, Kagemann L, Ciulla TA, Krieglstein GK. Atlas of Ocular Blood Flow: Vascular Anatomy, Pathophysiology, and Metabolism. Philadelphia, PA: Butterworth Heinemann; 2003
22 Malti PJ, Agarwal Geeta A. Comparative study of intraocular pressure changes with laryngeal mask airway and endotracheal tube. National Journal of Community Medicine 2012;3(2):279-282

23 Langham ME, Kitazawa Y, Hart RW. Adrenergic responses in the human eye. J Pharmacol Exp Ther 1971;179(1):47-55

24 Murphy DF. Anesthesia and intraocular pressure. Anesth Analg 1985;64(5):520-530 